\title{
Promoting Creativity of Government Officials of Macao Under the Guidance of Innovation Driven National Strategy of China \\ Li Jiazeng
}

Faculty of Humanities and Social Sciences, City University of Macao, 81 Av. Xian Xing Hai, Macau

\begin{abstract}
Early in 1911, the innovation theory was created by Austria political economist Joseph Alois Schumpeter. Innovation becomes a tendency of our era through the supplement and improvement by some successors. In the second decade of 21st century, the Innovation Driven Strategy has become an important strategic policy of the mainland of China. Macao is one of the two special administrative regions of People's Republic of China. In the situation of Innovation Driven National Strategy, it is a pressing matter of the moment for the government of Macao SAR to promote creative behavior and develop creativity of civil servants. It is important to recognize the spiritual nature of China's national strategy, to analyze the present situation of Macao government and its officials, and to explore effective ways to achieve this important goal.
\end{abstract}

Macao is one of the two special administrative regions of People's Republic of China. In the situation of Innovation Driven National Strategy, it becomes a pressing matter of the moment for the government of Macao SAR to promote creative behavior and develop creativity of civil servants. It is important to recognize the spiritual nature of China's national strategy, analyze the present situation of Macao government and its officials, and explore effective ways to achieve this important goal.

\section{Innovation Driven: from World Trend to National Strategy of China}

\section{The rise and development of innovation theory}

It is generally agreed that innovation means kinds of behavior or process to improve and create new things, methods and results by unconventional thinking methods and creative ideals. Innovation is the key concept of innovation driven theory. In order to understand the process of rise and development of innovation, we should trace back to about one century.

\section{The innovation theory derived from Schumpeter's Economic Development Theory}

In 1911, the famous Austria political economist Joseph Alois Schumpeter published his representative work, Economic Development Theory, and proposed firstly the concept of innovation and explained the basic frame of innovation theory. In his work, Schumpeter proposed to establish a new productive function called innovation. It means a re-combination of production factors. The function of capitalists as the soul of capitalism is to introduce the new combination and realize innovation. He considered innovation as the developing momentum of economic growth of capitalism, there will be no capitalism development without innovation [1].

As the innovation theory of Schumpeter emphasized to update economic structure, it grasped better the essence of economic development, and has had profound impacts since its formation.

\section{Neo-Schumpeterism economists developed the innovation theory}

After 1950s, with the rise of high tech revolution led by microelectronic technology, scientific and technological innovation became driving force for economic development. Under such circumstances, some economists inherited and developed Schumpeter's innovation theory, and it was called Neo-Schumpeterists.
There are two main genres of Neo-Schumpeterism. One is the periodic theory school of German economists. It thought that the economic recession and crisis forced companies to seek new technology, and the emergence of a large number of technological innovations had become the basis of economic development [2]. Another is the technical policy innovation school of British economists. It emphasized the stimulating effect of science and technology policy on technological innovation and proposed a theoretical system of scientific and technological policies playing an important role on technology innovation. In short, Neo-Schumpeterism emphasized the important function of technology and policy system to innovation [3].

\section{Formation of innovation driven strategy of China}

In China, the policy of "Reform and Opening up" has been implemented for more than 30 years. Recently the top leadership goes with the current of the times and puts forward timely the innovation driven economic developing strategy. Some related important events are as follows:

"Innovation Driven Strategy" was initiated at the 18th Congress of the Communist Party of China (CPC)

In November 2012, Mr. Hu Jintao, the Secretary General of CPC proposed in his report at the 18th Congress: "Implementing innovation driven development strategy. Science and technology innovation is the strategic support for improving social productivity and comprehensive national power. It must be placed in the core

"Corresponding Author: Prof. Li Jiazeng, Faculty of Humanities and Social Sciences, City University of Macao, 81 Av. Xian Xing Hai, Macau; E-mail: lijiazeng@cityu.mo

Citation: Jiazeng L (2017) Promoting Creativity of Government Officials of Macao Under the Guidance of Innovation Driven National Strategy of China. Int J Psychol Behav Anal 3: 129. doi: https://doi.org/10.15344/2455-3867/2017/129

Copyright: @ 2017 Jiazeng. This is an open-access article distributed under the terms of the Creative Commons Attribution License, which permits unrestricted use, distribution, and reproduction in any medium, provided the original author and source are credited. 
Citation: Knibbs C (2017) Cybertrauma: The Impact of the Online World on the Developing Brain and Interpersonal Struggles of Children, Young People and Adults too- Case Examples from Clinical Practice. Int J Psychol Behav Anal 3: 129. doi: https://doi.org/10.15344/2455-3867/2017/129

Page 2 of 5

position of national development [6]". This is the first appearance of "Innovation Driven Strategy" in China's authoritative documents.

Connotation of "Innovation Driven Strategy" was standardized by the Political Bureau of the Central Committee of CPC

On September, 30th, 2013, the Political Bureau of the Central Committee of CPC held the 9th collective learning conference with the theme of "Implementing Innovation Driven Development Strategy". The Secretary General Xi Jinping presided the learning himself and generalized the connotation of "Innovation Driven Strategy" as follows: 1 .To promote scientific and technological innovation and economic and social development closely, so that the market will truly become the power to allocate innovation resources and enterprises become the main body of technological innovation. 2. To enhance the ability of independent innovation, and to strive to grasp the key core technology, to improve the overall effectiveness of national innovation system. 3. To improve the talent development mechanism, to remove the institutional barriers to personnel flow and use, and to play a role in the mechanism, to maximize the support and help scientific and technological personnel innovation and entrepreneurship. 4. To create a good policy environment, to guide enterprises and society to increase R \& D investment, to strengthen the protection of intellectual property rights and improve the tax policy to promote technological innovation of enterprises. 5. To expand the cooperation of science and technology, to make full use of the global innovation resources and to promote independent innovation at a higher starting point [7].

\section{Innovation driven measures are implemented in Government Work Report}

Under the guidance of top decision of the party, the State Council of China implements the innovation driven strategy actively. In his Government Work Report of 2015, Premier Li Keqiang pointed out that the traditional power of economic growth was weakening recently and we must strengthen the structural reform and accelerate the implementation of innovation driven development strategy. He proposed some important initiatives, such as promoting scientific and technological innovation, taking enterprise as the subject of technological innovation, improving the efficiency of innovation and optimizing the allocation of scientific and technological resources, etc [8].

In short, the Innovation Driven Strategy has become an important strategic policy of the mainland of China. It will not only lead the economic development of the mainland in a very long period of time, but also have a major impact on the economic and social development of China's special administrative regions (SAR).

Innovation Driven: the necessity of socioeconomic development of Macao

As one of the two special administrative regions of the People's Republic of China, Macao has very close ties with the motherland. Facing the macro situation of the mainland to implement the innovation driven development strategy and from the actual situation of the SAR itself, Macao should also promote the economic and social sustainable development mechanism to gradually shift to the innovation driven track. Let us elaborate the reasons from the positive and the negative aspects.

\section{Development of the SAR should be synchronized with the main body of the state}

In China's SAR, "Basic Law" is the constitutional law. According to the "Basic Law" of Macao, Macao SAR is a non-separable part of the People's Republic of China. The purposes for establishing Macao SAR are to safeguard the unity and territorial integrity of the country, to keep the social stability and economic development of Macao, and also to take into account the history and reality of Macao. This shows that the main body of the country and the Macao SAR are organic unity of opposites, and there is an inseparable inner link between both sides.

At the same time, the main body of the country also makes some demands to the SARs. "The Twelfth Five Year Plan" of China has clearly pointed out: "To support Hong Kong and Macao to give full play to the advantages and continue to play important roles in the overall development of the country." In the 2015 government work report, Premier Li Keqiang pointed out again: "Continue to bring full use of the special roles of Hong Kong and Macao in the national reform and opening up and modernization construction." Therefore, in the national implementation of innovation driven development strategy premise, Macao SAR has the responsibility to actively cooperate with the main body of the country to develop simultaneously.

\section{Weak links of Macao should be urgently improved}

By contrast, there are some unavoidable weak links in Macao. It is lack of top-notch project in the city's comprehensive competitiveness, and there exists weak link in the competitive structure composition. City innovation ability is one of the weakest links. According to "Global Urban Competitiveness Report (2009 - 2010) - Innovation: the Inexhaustible source of urban competitiveness", even of comparison in the Pearl River delta range (mainly 8 cities including Shenzhen, Guangzhou, Zhuhai, Foshan, Dongguan, Zhongshan, Hong Kong, and Macao), the relevant data of Macao's "innovation output index" and "innovation ability" are all in the bottom position.

According to the index system of "global city competitiveness report", "Innovation ability" is composed by "R \& D funds accounted for GDP", "the added value of high-tech industry", "the number of patent applications" and "patent grant amount". The data of table 1 show that Macao is always located in the bottom position. It means the innovation ability of Macao is lower (even the lowest) than that of the other cities in the same region.

"Innovation output index" is made up of "patent application index", "patent index" and "GDP growth index". Table 2 lists the ranking of Innovation output index of 5 major cities in the Pearl River Delta region. It is also obvious that the innovation output ability of Macao is lower than that of the other cities in the same region.

From the above two aspects of the discussion, it is necessary for Macao to conform to the trend of the times with the strategic decision of the central government. And it is also necessary to consider its own actual situation, especially for some weak links, to develop appropriate policies and measures. In a word, Macao should transfer economic construction and social development mechanism gradually to the track of innovation driven. 
Citation: Knibbs C (2017) Cybertrauma: The Impact of the Online World on the Developing Brain and Interpersonal Struggles of Children, Young People and Adults too- Case Examples from Clinical Practice. Int J Psychol Behav Anal 3: 129. doi: https://doi.org/10.15344/2455-3867/2017/129

Page 3 of 5

\begin{tabular}{|c|c|c|c|c|c|c|c|c|}
\hline project related Innovation ability & Guangzhou & Shenzhen & Foshan & Dongguan & Zhongshan & Zhuhai & Chongqing & Macao \\
\hline R \& D expenditures accounted for GDP (\%) & 1.57 & 2.82 & 1.30 & 0.54 & 1.64 & 1.30 & 0.82 & 0.1 \\
\hline $\begin{array}{l}\text { added value of high and new technology } \\
\text { industry accounted for GDP (\%) }\end{array}$ & 1.575 & 3.236 & 0.988 & 1.132 & 2.392 & 1.596 & 0.870 & - \\
\hline Number of patent applications (pieces) & 13990 & 36261 & 13569 & 14406 & 6901 & 2244 & 10712 & 28 \\
\hline Patent grant amount (pieces) & 8081 & 18825 & 10677 & 8093 & 4342 & 1797 & 4871 & 6 \\
\hline
\end{tabular}

Table 1: Correlation data on innovation ability of main cities in the Pearl River Delta.

(Source: Referring to Chang Zhengzhou :"Research on Innovation Ability of Macao as an international city ")

\begin{tabular}{|l|l|l|l|l|l|l|l|l|}
\hline Urban innovation output index & Guangzhou & Shenzhen & Foshan & Dongguan & Zhongshan & Zhuhai & Chongqing & Macao \\
\hline Patent application index & 7 & 1 & 3 & 2 & 5 & 6 \\
\hline Patent index & 3 & 1 & 2 & 4 & 7 & 6 \\
\hline GDP growth index & 3 & 1 & 2 & 1 & 4 & 5 & 3 \\
\hline
\end{tabular}

Table 2: Innovation output index ranking of major cities in the Pearl River Delta.

(Source: converted from the data of "Global Competitiveness Report (2009-2010)")

Rational thinking of creativity development of government officials of Macao

The cadre is the deciding factor after the route and policy are determined. Whether the government of the Macao SAR can implement the innovation driven policy well, it depends on the innovation ability of the civil servants to a great extent. Thus, it is necessary to make a rational thinking of the innovation ability of Macao's civil servants.

\section{The necessity of cultivating the creativity of Macao civil servants}

Creative behavior is an important manifestation of creativity. The reasons why we should make great efforts to cultivate the creativity of Macao civil servants are mainly based on the following considerations.

Creative behavior is a necessary component of the quality of the civil service

Many scholars have put forward the concept of the civil servants' innovation ability. They think "The innovation ability of civil servants refers to the quality, the spirit and the outward manifestation of the subject in the innovation activities "; "Innovation ability is the ability a civil servant must have. It is not only a measure of the quality of civil servants and the level of core standards, but also the vigor and vitality source for the entire civil servants team to always maintain" [11].

In December 2003, the Ministry of Personnel of the state issued the "national civil service standards framework", and standardized civil service should have nine kinds of general ability. They are the ability of political identification, administrative ability, public service ability, research ability, learning ability, communication and coordination ability, innovation ability, the ability to deal with unexpected events, psychological debugging ability, respectively. The fact that the department of personnel of the main national considers innovation ability as one of the general provisions for civil servants requiring the government of Macao SAR to comply with.

The challenges facing Macao economic development create a need for improving the creativity of civil servants

The inherent problem of Macao's economy is that the gaming industry is the only strongest industry which is much more stronger than any other ones. In mid 2014, gaming industry revenue fell for the first time, leading to the first negative growth in GDP in 2015 after its return back to the motherland in 1999. Macao's economic development faces severe challenges. With conventional ideas and traditional methods, it will be very difficult to achieve the desired objectives to change this situation. "In measuring the local overall interests of Macao, we should not only focus on Macao's economic growth and tax revenue, but also take into account the economic and social security, stability and development interests of the mainland and the whole country" [12]. Therefore, it is very urgent for the government of Macao SAR to explore a new path of development on the basis of improving creativity of civil servants.

Improving creativity of civil servants is also the need of the government's new task

Many scholars pointed out the importance of creativity of civil servants. For example, "Creativity is one of the kinds of essential ability for civil servants. It is the core standard to measure the quality and level of civil servants, and is also the source of vitality of the team of civil servants" [11]. It is stressed that the relationship between civil servant creativity and government management."Civil servants assume the national administrative functions; innovation ability of civil servants directly affects government management level" [13]. These understandings have guiding significance to the construction of Macao Government Civil Service.

In the "Five year development plan" promulgated in September, 2016 the Macao SAR government created a new chapter in the economic construction and social development on the agenda. In order to adapt to this new situation, the majority of the civil service requirements will increase and it is inevitable to improve their creativity. However, the current civil service system originated in the period ruled by Portuguese 30 years ago, and many of the policies and measures especially for the training of civil servants were not paid enough attention and have been behind the needs of the times. So the 2016 policy address stressed: "to optimize the quality of the training work, to enhance the quality of public servants, and to be better for the construction of the SAR services." It is obvious that the creativity of civil servants should be an important measure to improve their quality. 
Citation: Knibbs C (2017) Cybertrauma: The Impact of the Online World on the Developing Brain and Interpersonal Struggles of Children, Young People and Adults too- Case Examples from Clinical Practice. Int J Psychol Behav Anal 3: 129. doi: https://doi.org/10.15344/2455-3867/2017/129

Page 4 of 5

The possibility of cultivating Macao civil servants' creativity

In Macao SAR, it is of a great possibility to train the creativity of civil servants with a large number of favorable conditions.

\section{The SAR government has always attached great importance to the} training of civil servants.

Since the reunification of the motherland, the SAR government has always been taking the improvement of the quality of civil service as an important measure to achieve the objectives of the policy. Even early in March, 2011, the chief executive Cui Shian pointed out in his first policy address: "making the system of civil servants training plan, increasing the administrative ethics of civil servants and professional ability training, developing high quality leadership and management personnel, training professional and technical personnel" [14]. This shows that the government has always attached importance to the training of civil servants. These conditions provide the basic guarantee for the training of civil servants' creativity.

The existing civil servant training system, institutions and mechanisms are effective

Macao SAR government not only attaches importance to the training of civil servants, but also has established an effective system, institutions and mechanisms to ensure the smooth progress of the civil service training. After the reunification of the motherland, the SAR government renamed the administrative office of public officials into "Administrative Office", an agency with the functions of research, planning and development of civil servants training and policy [15]. On February 8, 2012, membership in the public administration "Macao Civil Servant Training Center" subordinated to Administrative office of the public was set up. It means the training of civil servants of Macao has entered a new stage. The new training center will strengthen the overall function of the training work, integrate teaching resources, establish an efficient teaching staff, and strengthen the academic research work of public administration for enhancing the quality of public servants on the whole [16]. The existing institutions and mature mechanism can certainly provide effective carrier for the training of civil servants' creativity.

\section{A lot of favorable social forces in Macao SAR will help to develop creativity}

On the basis of the work of civil servant training, the Macao SAR government has been good at cooperation, with domestic and foreign forces to improve the quality of the training of civil servants. Singapore Institute of public service, Beijing Foreign Affairs University, etc. have been invited to host the training activities of the civil servants in Macao. Meanwhile, many scholars, university and social groups have always been committed to the theoretical research and practical exploration of the development of creativity and they can also become a variety of effective strength for the SAR government to train creativity of civil servants.

\section{Countermeasures and suggestions for creativity promoting and} developing of government officials of Macao

The necessity and possibility of training creativity of civil servants decided the inevitability of the work in Macao. In order to effectively cultivate creative behavior and improve creativity of the civil servants and to optimize the administrative effect of the SAR government, some recommendations are hereby made as follows:
Sounding the public service system and perfecting the evaluation index

Whether the creativity of civil servants can be developed or not depends mainly on whether the civil service system is perfect or not. Although the SAR government has always attached great importance to the improvement and perfection of the public service system, there are only the official entry requirements of academic qualifications, professional knowledge, work experience, language ability and other aspects of the provisions in the current public service system. There is neither any content about quality or ability, nor innovative capacity requirements. In order to meet the needs of the development of the situation, it is clear that the requirements of the quality and ability of creativity and innovation should be included in the compulsory requirements on civil servants.

At the same time, the evaluation index of civil servants should also be improved. It is important to improve the performance evaluation system of leaders, to achieve the combination of accountability system and the performance evaluation system of officials. When assessing the performance of officials, creative behavior, creativity and innovation results should be regarded as important contents, in order to produce a guiding role.

\section{Changing the concept of talent and advocating innovation} consciousness

In the Macao SAR, the evaluation of public servants at all levels and the mechanism of promotion of public servants essentially reflect the concept of the government of talent use. Under the current "official staff system", the main basis of promotion of civil servants at all levels is reinstated in order or rank and length of service in addition to evaluation of no less than the comment of "satisfied". This system is short of effective mechanism for the promotion of civil servants due to higher creativity or outstanding achievements in the work.

Public servants with higher creativity are often able to make a greater contribution through the creative behavior and achievement in their own position than the people around. A scientific and reasonable service system should provide greater convenience for such people. Therefore, we should not only require civil servants to fulfill their duties, but also advocate the consciousness of innovation. We should encourage them to reform with keen determination, bold innovation, and strive to make a special contribution. At the same time, the system should also fully affirm their creative work and the corresponding results. We should provide them with a more favorable promotion opportunities, and strive to fully guarantee the legitimate rights and interests of creative talents.

\section{Enriching the training institutions and improving training level}

Macao civil servant training center was established 4 years ago. The center has carried out a great deal of work in the training of civil servants and has achieved remarkable results in the past 4 years. However, this center is a departmental level administrative institution under the Administrative Office Bureau, instead of an official educational institution with complete function. We propose to refer to the system and experience of the Mainland and some other countries to establish "Macao Institute of Administration " on the basis of Macao civil servant training center. Thus we can gradually carry out full-time higher education, to train undergraduate and graduate students (such as MPA) majoring in public administration. 
Citation: Knibbs C (2017) Cybertrauma: The Impact of the Online World on the Developing Brain and Interpersonal Struggles of Children, Young People and Adults too- Case Examples from Clinical Practice. Int J Psychol Behav Anal 3: 129. doi: https://doi.org/10.15344/2455-3867/2017/129

Page 5 of 5

Only in this way can we adapt to the needs of the development of the situation and government policy science. When the civil servants training and education have gradually got back on track, and the level of creativity development will also be justifiably implemented.

\section{Implementing the policy of pluralism and integrating the social forces}

According to the actual conditions of the Macao SAR, the training of civil servants' creativity can be carried out with the policy of pluralism at the present stage. It is necessary to allow the social forces with appropriate conditions to actively participate in the training of civil servants.

As for the training host, in addition to powers from foreign or outside of the SAR, the enthusiasm of the local forces should also be mobilized. There are a lot of local units such as colleges and universities, social groups, enterprises and institutions, which possess favorable conditions to carry out the training of the civil servants especially in creativity developing. On the basis of investigation and study, the SAR government should first tap the local resources. It is necessary to seek a variety of forms of cooperation, collaboration, trust, project, bidding, etc. to promote the public servants training and education in the diversified development. If it can really be the case above, the promotion of creativity of civil servants, the overall optimization of the civil service team of Macao SAR, must be able to achieve significant results in the near future.

\section{Conclusion}

Under the influence of Schumpeter's innovation theory originated more than 100 years ago, China has identified innovation driven as guidelines for economic development. In order to synchronize the state subject, Macao, a special administrative region of China, should grasp the important link of civil servant creativity development. For Macao, the development of civil servants creativity is not only very necessary, but also has many favorable conditions. There are 4 effective ways to increase the creativity of civil servants. They are"sounding the public service system and perfecting the evaluation index", "changing the concept of talent and advocating innovation consciousness", "enriching the training institutions and improving training level" and "implementing the policy of pluralism and integrating the social forces". The gradual strengthening of civil servants' creativity will certainly have a positive role in promoting the economic construction and social development of Macao.

\section{Competing Interests}

The authors declare that they have no competing interests.

\section{References}

1. Entry " Schumpeter's innovation theory".

2. Daiguang $H$, Yining $L$ (1982) The Contemporary Bourgeois Economics Major Schools. Beijing: the Commercial Press.

3. Liqun J, Xu L, Yingluo $W$ (1995) Research progress on the new Schumpeter School of thought on technological and economic innovation theory. China Science and Technology Forum 05: 38-41.

4. Peijing D (1986) Guilford on creativity, Psychological development and education 2: 42-45.

5. Jiazeng L (2002) Creative Study and creativity development. Nanjing: Jiangsu people's publishing house. Second edition.
6. Jintao H (2012) Unswervingly follow the road of socialism with Chinese characteristics and strive to build a moderately prosperous society in an allround way- a report on the eighteenth National Congress of the Communist Party of China.

7. Jinping $X(2013)$ The implementation of innovation driven can't wait to wait and see slack.

8. Keqiang L (2015) government work report in 2015 .

9. Jiazeng $L$ (2015) Macao how to enhance the innovation capability and competitiveness of the city? Nine Tripods 03: 5-8.

10. Xiaojun D, Zhiqi $\mathrm{H}$, Huili $\mathrm{H}$ (2007) The construction of the evaluation index system of Chinese civil servants' innovation ability in the new century. The development research 5: 65-69.

11. Haibing Z, Wenli W (2011) On the innovation ability of civil servants. The administration and law 3: 63-65.

12. Fei $L$ (2014) The basic law of Macao and the development of the special region. Macao daily, B10 edition.

13. Hongguang $Z$ (2014) Reflections on improving the innovation ability of civil servants. Economic and technical cooperation information 36: 22-23.

14. Shian C (2010) The fiscal year 2010 policy address.

15. Administrative office

16. Macao official training center unveiled, Chinese News Network. 